\title{
Development of broad-range 16S rDNA PCR for use in the routine diagnostic clinical microbiology service
}

\author{
Kathryn A. Harris and John C. Hartley

\section{Department of Microbiology, Level 4 Camelia Botnar Laboratories, Great Ormond Street Hospital for Children NHS Trust, Great Ormond Street, London WC1N 3JH, UK}

Correspondence

Kathryn A. Harris

harrik2@gosh.nhs.uk

\begin{abstract}
The aim of the present study was to develop a broad-range PCR based on bacterial 16S rDNA for use in the routine diagnostic clinical microbiology service. The optimization and validation of the assay for use on clinical specimens from normally sterile sites is described, and preliminary results are reported on the use of the assay in the clinical diagnosis of bacterial infection in 382 paediatric specimens over a 2-year period. These results are compared to those obtained by standard culture techniques and show increased diagnosis of bacterial infection when both culture and PCR are used together; $16 \mathrm{~S}$ rDNA PCR provided the sole evidence of pathogenic infection in 71 cases. Key stages in the assay development and potential pitfalls of the technique are highlighted and the improvement the assay offers in the diagnosis of infection in the paediatric setting is discussed.
\end{abstract}

Received 7 February 2003

Accepted 19 April 2003

\section{INTRODUCTION}

Accurate diagnosis of bacterial infection leads to appropriate patient management, providing information on prognosis and allowing the use of narrow-spectrum antibiotics. This in turn reduces side-effects for the patient, saves money and may slow the spread of antibiotic resistance (Gould, 1999, 2002). Some bacterial species, however, are difficult to isolate, or grow slowly in the laboratory due to stringent growth requirements, while others may not grow because of prior empirical treatment of patients with antimicrobial agents. Molecular diagnostic techniques, such as PCR, are being developed to aid in the diagnosis of bacterial infection by detecting bacterial genetic material (Fredricks \& Relman, 1999). Unlike culture, most molecular assays are designed specifically for one organism. This provides high sensitivity and specificity but detects only what you are looking for; multiple assays may be required to screen for multiple organisms. Broad-range assays, based on ribosomal genes (rDNA), are designed to overcome this limitation. Bacterial rDNA consists of highly conserved nucleotide sequences that are shared by all bacterial species, interspersed with variable regions that are genus- or species-specific. The DNA sequences of the variable regions form the basis of phylogenetic classification of microbes (Doolittle, 1999). By using PCR primers that are targeted at conserved regions of rDNA, it is possible to design broad-range PCRs capable of detecting DNA from almost any bacterial species. The identity of the bacterium captured is revealed by nucleotide sequencing of the PCR product followed by comparison of this sequence with known sequences located in GenBank or other data-

Abbreviations: CNS, coagulase-negative staphylococci; GOSH, Great Ormond Street Hospital. bases (Drancourt et al., 2000; Janda \& Abbott, 2002). Furthermore, previously uncharacterized bacteria are revealed by the detection of novel sequences. Under research conditions, this approach has been applied to samples from normally sterile sites to diagnose bacterial infection, including meningitis, pneumonia and bacteraemia, when culture results proved negative (Lu et al., 2000; Rantakokko-Jalava et al., 2000; Trotha et al., 2001; Nikkari et al., 2002; Yamamoto, 2002). In addition to this, uncultured bacteria have been identified as the aetiological agent in a number of diseases, for example Tropheryma whippelii in Whipple's disease (Wilson et al., 1991; Relman et al., 1992; La Scola et al., 2001). Broadrange bacterial PCRs are more prone to contamination with exogenous DNA than other PCR assays and extra precautions must be taken to ensure that accurate results are obtained (Millar et al., 2002).

To be useful in a routine clinical microbiological service the assay should be able to amplify rDNA from all common pathogens, correctly identify species in original sample from the PCR product and be sufficiently sensitive to detect organisms when routine methods fail. Moreover, the clinician needs to be confident that the assay does not detect DNA from potentially pathogenic micro-organisms when not significant, for example, due to the presence of DNA in the reagents, due to unavoidable introduction of contamination during sample collection and handling or because bacterial DNA is insignificantly present at normally sterile sites. Finally, the assay procedure must be robust enough to work in the routine setting and swift enough to produce a clinically useful result.

We describe the development of a broad-range PCR, based on bacterial $16 \mathrm{~S}$ rDNA, for use in the routine diagnostic clinical microbiology service. We include a preliminary 
report on its use in the clinical diagnosis of bacterial infection in children over a 2-year period at Great Ormond Street Hospital (GOSH), London, and compare our results to those obtained by standard culture methods. We discuss where the technique may offer an improvement in the diagnosis of bacterial infection in a paediatric setting when employed alongside standard culture techniques.

\section{METHODS}

Control organisms. Isolates of one or more members of the genera listed below were used as control organisms for the PCR (isolates were tested from pure culture propagated on solid media or in cell culture as appropriate, or obtained as lyophilized type strains): Acinetobacter, Actinomyces, Agrobacterium, Alcaligines, Bacillus, Brevibacterium, Burkholderia, Campylobacter, Capnocytophaga, Cardiobacterium, Chlamydia, Chlamydophila, Chryseomonas, Clostridium, Comamonas, Corynebacterium, Escherichia, Eikenella, Enterococcus, Flavobacterium, Fusobacterium, Haemophilus, Klebsiella, Lactobacillus, Leptotrichia, Leuconostoc, Listeria, Moraxella, Mycobacterium, Mycoplasma, Neisseria, Nocardia, Pandorea, Paenibacillus, Pasteurella, Peptostreptococcus, Propionibacterium, Providencia, Pseudomonas, Ruminococcus, Salmonella, Sphingobacterium, Sphingomonas, Staphylococcus, Stenotrophomonas, Stomatococcus, Streptococcus, Tropheryma, Ureaplasma, Veillonella and Vibrio. A crude DNA extract was prepared as follows: 2-6 bacterial colonies, a small amount of cell culture or resuspended lyophilized type strain were suspended in $1 \mathrm{ml}$ sterile saline and either incubated at $95{ }^{\circ} \mathrm{C}$ for $10 \mathrm{~min}$ or mechanically disrupted using a Ribolyser (Hybaid) with Ribolyser resin for lysis of bacterial cells. Lysed suspensions were then centrifuged at $20000 \mathrm{~g}$ for $1 \mathrm{~min}$. One microlitre of the supernatant was amplified in the PCR.

Quantification. Suspensions of Escherichia coli (NCTC 10418) and Staphylococcus aureus (NCTC 6571) isolates were prepared as described above and the number of colony forming units present estimated by plate counts (Miles \& Misra, 1938). DNA was extracted from the original suspension, as described above, and serial tenfold dilutions were amplified in the PCR.

Amplification. The PCR reaction mixture was as follows: $1 \times$ PCR buffer, $1.5 \mathrm{mM} \mathrm{MgCl}_{2}, 0.1 \mathrm{mM}$ dNTPs, $1 \mathrm{U}$ Taq polymerase (all Invitrogen), $0.4 \mu \mathrm{M}$ of each of the following primers: $16 \mathrm{SFa}: 5^{\prime}-$ GCTCAGATTGAACGCTGG-3'， 16SFb: $5^{\prime}$-GCTCAGGAYGAACG CTGG-3', 16SR: 5'-TACTGCTGCCTCCCGTA-3' (Harris et al., 2002) and sterile UV-irradiated water to give a final volume of $45 \mu \mathrm{l}$. Five microlitres of extracted DNA and $5 \mu \mathrm{l}$ extracted DNA diluted 1-in10 were added to two separate aliquots of this mixture and the reactions were heated to $94{ }^{\circ} \mathrm{C}$ for $3 \mathrm{~min}$, followed by $25-35$ cycles of $94{ }^{\circ} \mathrm{C}$ for $30 \mathrm{~s}, 63^{\circ} \mathrm{C}$ for $1 \mathrm{~min}$ and $72{ }^{\circ} \mathrm{C}$ for $1 \mathrm{~min}$. A final extension was carried out at $72{ }^{\circ} \mathrm{C}$ for $5 \mathrm{~min}$.

PCR controls. To control for PCR inhibition a 'spiked' control was performed for each extracted sample by adding $1 \mu$ Escherichia coli positive control $\left(\sim 100\right.$ c.f.u. $\left.\mu \mathrm{l}^{-1}\right)$ along with $5 \mu \mathrm{l}$ of the extracted sample to a third PCR reaction. Sterile UV-irradiated water was used as amplification target in a fourth reaction as a negative control. Each PCR run included two positive controls $(1 \mu \mathrm{l}$ each of Escherichia coli $\sim 100$ c.f.u. $\mu \mathrm{l}^{-1}$ and Staphylococcus aureus $\sim 100$ c.f.u. $\mu \mathrm{l}^{-1}$ ).

Amplicon detection. PCR reactions were electrophoresed through a $2 \%$ agarose gel containing $2 \mu \mathrm{l} 500 \mathrm{nM}$ ethidium bromide and bands were visualized by UV transillumination.

UV irradiation of PCR reagents. PCR reaction mixtures were prepared as described above but with the primers and DNA template omitted. Reaction mixtures were UV-irradiated at a distance of $20 \mathrm{~cm}$ from a $254 \mathrm{~nm}, 15 \mathrm{~W}$ UV light source for $0,5,10,20$ and $30 \mathrm{~min}$. Primers and template (either Escherichia coli positive control DNA or sterile, UV-irradiated negative control water) were then added. Reaction mixtures were then subjected to the cycling conditions described above.

Sequencing. Positive PCR reactions were sequenced with the ABI PRISM Big-dye sequencing kit and analysed on the ABI 377 Genetic Analyzer (PE Applied Biosystems).

Cloning of PCR products. Where the direct sequence of a PCR product indicated a mixture of $16 \mathrm{~S}$ rDNA sequences from different bacterial species, PCR cloning was performed using the TOPO-TA cloning kit (Invitrogen). Individual colonies were amplified directly by PCR using the M13 forward (-20) and reverse priming sites and three resulting amplicons of the correct size were sequenced, as described above, using primers T3 and T7.

Clinical specimens. Between 31 October 1999 and 1 November 2001, 382 selected clinical specimens from children at GOSH, and referred paediatric specimens, were tested for the presence of bacterial DNA by our broad-range $16 \mathrm{~S}$ rDNA PCR, in addition to routine microbiological culture. Adequate material was submitted for routine culture first, residual material was processed for $16 \mathrm{~S}$ rDNA PCR, frequently resulting in less specimen being processed for PCR than for culture. The assay was not performed in a comparative study of sequential specimens but specimens were selected when clinical and other laboratory variables suggested a higher likelihood of infection. 16S rDNA PCR was initially run in parallel with culture, but subsequently 16S PCR was delayed until primary culture was completed. Results were generated real time, within the constraints of the service, and discussed by the Clinical Microbiology service with clinicians responsible for each case on an individual basis.

DNA extraction from clinical specimens. Genomic DNA was extracted from a range of clinical samples including tissue, pus, blood, cerebrospinal fluid and other body fluids using the QIAmp DNA mini kit (Qiagen), following either the body fluid or tissue extraction protocol as appropriate. An additional incubation at $95{ }^{\circ} \mathrm{C}$ for $15 \mathrm{~min}$ was performed following the Proteinase $\mathrm{K}$ digestion to ensure compete lysis of bacterial cells. However, for all samples processed after 1 October 2000 this step was performed mechanically using a Ribolyser cell disrupter (Hybaid) according to the manufacturer's instructions. Briefly, following Proteinase K digestion, Ribolyser resin for bacterial cells was added to the sample (approx. one quarter of an individual aliquot) and the sample was placed in the Ribolyser and run at maximum speed for $40 \mathrm{~s}$. One negative control $(200 \mu \mathrm{l}$ sterile, UVirradiated water) was included in each extraction run.

Conventional microbiological methods. GOSH has a Clinical Pathology Accreditation (UK) accredited laboratory providing a comprehensive microbiological and virological service. Samples were processed by a range of routine microbiological methods. Tissues and all fluids (except urines) were cultured directly and after enrichment in overnight broth culture; tissue broths were further subcultured after 5 days. (Broths were inoculated using sterile techniques on the open bench.) Where appropriate bacterial antigens were sought in cerebrospinal fluid and serum by latex agglutination (Murex Biotech). Isolates were identified by routine tests, API (bioMérieux) or referred to a reference laboratory if conventional identification was unsuccessful.

Bacterial identification. The identities of bacteria detected by the $16 \mathrm{~S}$ rDNA PCR were revealed by sequencing of the PCR products and comparison of these sequences to the GenBank database using the BLAST program available at the National Center for Biotechnology Informa- 
tion (http://www.ncbi.nlm.nih.gov). While molecular phylogeny based on the ribosomal genes is the reference standard for bacterial classification, there are no universally accepted criteria for the level of homology expected between $16 \mathrm{~S}$ rDNA from different isolates of bacteria from the same species or genera. A recent report suggested $99-100 \%$ similarity over the 16S rDNA for members of the same species and $97-99 \%$ for members of the same genus (Drancourt et al., 2000). When comparing the $320 \mathrm{bp}$ sequence generated in this assay with publicly available sequences we have used these figures as guidelines in assigning a species or genus name to a $16 \mathrm{~S}$ rDNA sequence. In addition to BLAST analysis sequences were also compared to an in-house database of bacterial $16 \mathrm{~S}$ rDNA sequences using the CLUSTAL algorithm in the MEGALIGN computer program (DNAStar, Madison, WI, USA). When used together these methods can identify most bacteria to species level and all bacteria to genus level, with the exception of novel bacterial sequences. Unusual sequences can be investigated further by sequencing of the entire 16S rDNA (Harris et al., 2002).

\section{RESULTS}

\section{Assay development}

Primers $16 \mathrm{SFa}$ /16SFb and 16SR amplify a 320 bp hypervariable region at the $5^{\prime}$ end of the bacterial $16 \mathrm{~S}$ rDNA. Comparison of these primer sequences with bacterial $16 \mathrm{~S}$ rDNA sequences in the GenBank database shows that they are complementary to a wide range of different bacterial genera and species (data not shown). The theoretical broad-range of these primers was validated by successful amplification of $>100$ characterized laboratory isolates, one or more species from each of the genera listed in Methods were tested. Several of these isolates also had their identity confirmed at a reference laboratory, were quality control isolates or were NCTC strains.

PCR reagents, sterile UV-irradiated water, buffer, $\mathrm{MgCl}_{2}$, dNTPs and Taq polymerase were subjected to UV irradiation prior to amplification of either Escherichia coli DNA or a negative control (sterile UV-irradiated water). Table 1 shows the PCR result obtained for a range of different UV irradiation times and PCR cycle numbers.

UV irradiation of the PCR reagents for $10 \mathrm{~min}$ or more resulted in the negative control consistently giving a negative PCR result. However, it also resulted in failure to detect the positive control at 25 cycles when UV irradiation was carried out for $10 \mathrm{~min}$, at 25 and 30 cycles when UV irradiation was carried out for $20 \mathrm{~min}$ and at 25, 30 and 35 cycles when irradiation was carried out for $30 \mathrm{~min}$.

The experiment was repeated with UV irradiation of only the sterile water, PCR buffer and $\mathrm{MgCl}_{2}$ (Table 1). This resulted in the negative control giving a positive result at 30 and 35 cycles, but a negative result at 25 cycles when UV irradiation was carried out for $5 \mathrm{~min}$ or longer. The positive control was detected with all UV irradiation times and cycle numbers. Further experiments showed that following UV irradiation of sterile water, PCR buffer and $\mathrm{MgCl}_{2}$ for $5 \mathrm{~min}$, a maximum of 26 PCR cycles could be performed at which negative controls gave a consistently negative result (data not shown).
Table 1. Amplification of bacterial DNA from positive and negative controls following UV irradiation of PCR reagents for varying lengths of time and increasing number of PCR cycles

Detection of bacterial PCR products by gel electrophoresis and UV transillumination: + , positive; + /-, low level; - , none detected.

\begin{tabular}{|c|c|c|c|c|c|}
\hline \multirow[t]{2}{*}{$\begin{array}{l}\text { UV } \\
(\mathrm{min})\end{array}$} & \multirow[t]{2}{*}{$\begin{array}{l}\text { PCR } \\
\text { cycles }\end{array}$} & \multicolumn{2}{|c|}{$\begin{array}{c}\text { Irradiation of water, } \\
\text { buffer, } \mathrm{MgCl}_{2}, \\
\text { dNTPs and Taq }\end{array}$} & \multicolumn{2}{|c|}{$\begin{array}{l}\text { Irradiation of water, } \\
\text { buffer and } \mathrm{MgCl}_{2}\end{array}$} \\
\hline & & $\begin{array}{c}\text { +ve } \\
\text { control }\end{array}$ & $\begin{array}{c}\text {-ve } \\
\text { control }\end{array}$ & $\begin{array}{c}\text { +ve } \\
\text { control }\end{array}$ & $\begin{array}{c}\text {-ve } \\
\text { control }\end{array}$ \\
\hline \multirow[t]{3}{*}{0} & 25 & + & $+1-$ & + & + \\
\hline & 30 & + & + & + & + \\
\hline & 35 & + & + & + & + \\
\hline \multirow[t]{3}{*}{5} & 25 & + & - & + & - \\
\hline & 30 & + & - & + & + \\
\hline & 35 & + & + & + & + \\
\hline \multirow[t]{3}{*}{10} & 25 & - & - & + & - \\
\hline & 30 & + & - & + & + \\
\hline & 35 & + & - & + & + \\
\hline \multirow[t]{3}{*}{20} & 25 & - & - & + & - \\
\hline & 30 & - & - & + & + \\
\hline & 35 & + & - & + & + \\
\hline \multirow[t]{3}{*}{30} & 25 & - & - & + & - \\
\hline & 30 & - & - & + & + \\
\hline & 35 & - & - & + & + \\
\hline
\end{tabular}

Following optimization, the resulting PCR conditions were UV irradiation of the sterile water, PCR buffer and $\mathrm{MgCl}_{2}$ at a distance of $20 \mathrm{~cm}$ from a $254 \mathrm{~nm}$ UV light source for $10 \mathrm{~min}$. Primers (16Sfa, 16SFb and 16SR), Taq polymerase, dNTPs and template DNA were then added. Reaction mixtures were then subjected to the cycling conditions described above, with 26 cycles.

Using the optimized PCR conditions and isolates enumerated as colony-forming units, the sensitivity of the PCR was estimated to be 10-100 c.f.u. per reaction for Escherichia coli suspensions and 100-1000 c.f.u. per reaction for Staphylococcus aureus suspensions when bacterial cells were lysed by incubating at $95^{\circ} \mathrm{C}$. When mechanical disruption was used as the method of cell lysis, the sensitivity of the PCR was estimated to be 10-100 c.f.u. per reaction for both Escherichia coli and Staphylococcus aureus.

The sensitivity of the optimized PCR was compared to other single-target bacterial PCRs that are run in-house. The $16 \mathrm{~S}$ rDNA PCR was 10 -fold more sensitive than a 30 cycle PCR for the penicillin-binding protein (PBP) $2 \mathrm{~b}$ gene in Streptococcus pneumoniae (1400 bp product). However, its sensitivity was similar to that of a 35-cycle PCR for vancomycinresistant enterococci (350 bp product) and 50-fold less sensitive than a nested 70-cycle PCR for $\beta$-haemolytic streptococci (250 bp product). 


\section{Comparison of broad-range 16S rDNA PCR and standard culture techniques - a preliminary analysis}

A total of 382 clinical specimens from children referred to GOSH and referred paediatric specimens were tested for the presence of bacterial DNA by our broad-range $16 \mathrm{~S}$ rDNA PCR in addition to routine microbiological culture. These specimens comprised 30 blood samples, 123 cerebrospinal fluid samples, 79 tissues, 69 pus samples, 23 pleural fluids, seven peritoneal dialysis fluids, six bronchoalveolar lavages, three blood culture fluids and 42 other fluids.

An overall comparison of culture and PCR results is shown in Fig. 1, with further analysis of subgroups $(\mathrm{A}-\mathrm{F})$ below. A total of 205 specimens were both culture- and PCR-negative (A); no further analysis of these results is provided here. Nineteen specimens were culture-positive and negative by PCR (B) (Table 2). A further 25 specimens were positive on enrichment culture but PCR-negative (C); the majority of these (18/25) were coagulase-negative staphylococci (CNS), common laboratory contaminants (Table 2).

Sixty-three samples were both culture-positive (primary or enrichment) and PCR-positive. In 34 cases the identities of the bacteria were concordant (D) and in 29 samples discordant (E). Of the 29 discordant samples, culture and PCR results were entirely different in 23 samples; of these, 13 (two primary culture-positive and 11 enrichment culturepositive) grew only CNS but were PCR-positive for a potential human pathogen, determined to be clinically significant by clinical review (Table 3). In 10 of the 23 samples, PCR detected an organism other than a clinically significant organism detected by culture. In the remaining six discordant samples additional organisms were detected by either PCR (four samples) or culture (two samples).

Seventy samples were primary and enrichment culturenegative and PCR-positive (F), some with more than one
Table 2. Organisms that grew in primary or enrichment cultures but were not detected by 165 rDNA PCR

Data are number of samples.

\begin{tabular}{|lcc|}
\hline Organism & Primary & Enrichment \\
\hline Staphylococcus aureus & 6 & 2 \\
Coagulase-negative staphylococci & 3 & 18 \\
Pseudomonas sp. & 2 & 1 \\
Mycobacterium sp. & 2 & - \\
Aspergillus sp. & 1 & - \\
Citrobacter sp. & 1 & - \\
Gemella sp. & 1 & - \\
Pasteurella sp. & 1 & - \\
Streptococcus sp. & 1 & - \\
Mixed flora & 4 & - \\
Corynebacterium sp. & - & 2 \\
Candida albicans & - & 1 \\
Unidentified Gram-positive rod & - & 1 \\
Total & 22 & 25 \\
\hline
\end{tabular}

bacterial species. A potential human pathogen, determined clinically significant by clinical review, was detected 58 times from 70 samples (Table 4).

\section{DISCUSSION}

Molecular techniques are needed to improve the diagnosis of bacterial infection in specimens rendered culture-negative either by prior empirical antibiotic treatment or due to the presence of fastidious organisms. In this study a broad-range $16 \mathrm{~S}$ rDNA PCR was developed for the detection of bacterial 16S rDNA in clinical specimens and the PCR conditions were optimized to obtain the highest level of sensitivity whilst

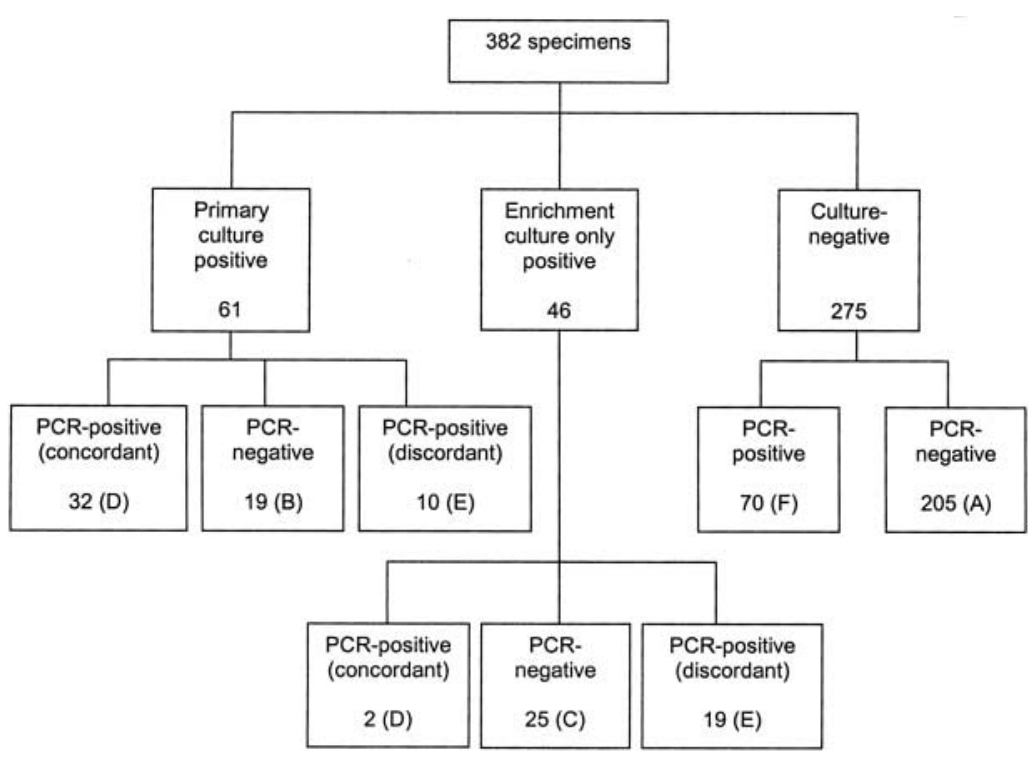

Fig. 1. Broad-range $16 S$ rDNA PCR and sequencing vs standard culture techniques for the detection of bacteria in 382 clinical specimens. 
Table 3. Potential human pathogens, determined to be clinically significant by clinical review, detected by $16 \mathrm{~S}$ rDNA PCR in samples that grew only CNS

\begin{tabular}{|lc|}
\hline Organism & No. samples $^{\star}$ \\
\hline Streptococcus pneumoniae & 4 \\
Peptostreptococcus sp. & 2 \\
Staphylococcus aureus & 2 \\
Streptococcus pyogenes & 2 \\
Streptococcus intermedius & 1 \\
Ureaplasma urealyticum & 1 \\
Fusobacterium necrophorum & 1 \\
\hline
\end{tabular}

${ }^{\star}$ Each from a different patient.

Table 4. Organisms detected by $16 \mathrm{~S}$ rDNA PCR in culturenegative specimens

\begin{tabular}{|lc|}
\hline Organism & No. samples $^{\star}$ \\
\hline Streptococcus pneumoniae $\dagger$ & $22(20)$ \\
Mycoplasma orale $\dagger$ & $6(2)$ \\
Streptococcus pyogenes $\dagger$ & $4(3)$ \\
Haemophilus influenzae $\dagger$ & 4 \\
Staphylococcus epidermidis & 4 \\
Neisseria meningitidis $\dagger$ & 3 \\
Propionibacterium acnes & 3 \\
Staphylococcus aureus $\dagger$ & 3 \\
Acidovorax sp. & 2 \\
Corynebacterium sp. & 2 \\
Streptococcus agalactiae $\dagger$ & 2 \\
\hline
\end{tabular}

${ }^{*}$ No. patients where different is given in parentheses.

$\dagger$ Potential human pathogen, determined to be clinically significant by clinical review.

avoiding false-positive results from ubiquitous bacterial DNA contamination. Bacterial DNA contamination of PCR reagents, most notably Taq polymerase, is well documented (Bottger, 1990; Meier et al., 1993; Corless et al., 2000; Lyons et al., 2000). Taq polymerase has a high affinity for DNA, which is co-purified during enzyme production. This contamination is difficult to remove by downstream purification methods and consequently commercially available Taq polymerases contain some bacterial DNA; the DNA is of unknown origin and not from a single organism (Corless et al., 2000). Several investigators have reported this problem in broad-range bacterial PCR, and have attempted to overcome it by a number of different procedures to 'clean-up' PCR reagents, most notably UV irradiation (Meier et al., 1993; Corless et al., 2000). Although such procedures may appear to be effective, we have shown that UV irradiation of PCR reagents reduces the sensitivity of the subsequent PCR assay, presumably due to degradation of the polymerase. A recent study (Corless et al., 2000), using real-time PCR technology, showed that such treatments reduced the threshold value $\left(C_{\mathrm{T}}\right)$ of the PCR by approximately $2-4 \log$ units, the equivalent of 6-12 PCR cycles. This and another real-time PCR study (Nadkarni et al., 2002) concluded that reducing the number of PCR cycles is the most effective way of avoiding the amplification of contaminant DNA that gives false-positive results. To limit the detection of inherent bacterial contamination, we elected to irradiate water, nucleotides and buffers with UV, and the number of cycles was limited to 26. Sensitivity comparisons show this does lead to some reduction in sensitivity compared to specific PCRs. Until ultrapure Taq polymerases are available, broadrange $16 \mathrm{~S}$ rDNA PCR is unsuitable for detecting low numbers of organisms or for accurate quantitative real-time PCR.

Bacterial classification is an evolving science that, for the clinical microbiologist, should enable the establishment of usable and reproducible identification schemes for commonly encountered species. While traditionally based on phenotypic characteristics, classification is now increasingly reliant on genotype and old and new species can be defined by their rDNA sequences. While there is agreement on the importance of rDNA sequence analysis, there is not universal agreement on the degree of sequence divergence permissible within a species or genus. Suggested cut-off values based on whole 16S rDNA sequences (Drancourt et al., 2000; Janda \& Abbott, 2002) are 99-100\% similarity for members of the same species and 97-99\% for members of the same genus. This may be used as a guideline in assigning a species or genus name to a $16 \mathrm{~S}$ rDNA sequence. In reality these figures will vary between genera. Some phenotypically distinct species share up to $100 \%$ identity in their $16 \mathrm{~S}$ rDNA sequences (e.g. Escherichia coli and Shigella sonnei, Bacillus anthracis and Bacillus cereus). Conversely, some strains considered to be members of the same species vary in their 16S rDNA sequence by $>1 \%$. Assigning a species based on $16 \mathrm{~S}$ rDNA sequence is also difficult, as not all bacterial species have representative $16 \mathrm{~S}$ rDNA sequences in the GenBank database. Sequences that diverge by greater than $1 \%$ from the closest match in the database may represent novel bacterial species or simply reflect the incomplete status of the database. An in-house database can address this problem by including $16 \mathrm{~S}$ rDNA sequences from the missing species within a genus, following in-house sequencing of wellcharacterized strains. Rigorous analysis would be necessary in order to conclude that a $16 \mathrm{~S}$ rDNA sequence is derived from a novel species.

In this study the 320 bp hypervariable region at the $5^{\prime}$ end of the $1400 \mathrm{bp} 16 \mathrm{~S}$ rDNA was used. The criteria used to assign a species name were $98-100 \%$ similarity to more than one GenBank sequence of the same species and/or tight clustering with members of one species in the in-house database using the CLUSTAL algorithm in the MEGALIGN program. Sequences not meeting these criteria but with $>95 \%$ similarity to more than one GenBank sequence of the same genus and/or tight clustering within one genus in the in-house database were assigned an identity to the genus level only. Using these 
criteria most potentially pathogenic bacteria from identified cultures were successfully identified to species level. In this study the vast majority of bacterial sequences from clinical specimens were identified to at least the genus level and most of these to the species level. Unidentified sequences are occasionally encountered; the significance of these is unknown at this stage. A further consideration is that GenBank is a public database containing a vast number of $16 \mathrm{~S} \mathrm{rDNA}$ sequences; consequently, there is no control over who submits data and whether it is accurate. A $16 \mathrm{~S}$ rDNA sequence submitted to the database could be incorrectly named and care must be taken when identifying bacteria on this basis. In order to be confident that a sequence was correctly identified, we required matches with several $16 \mathrm{~S}$ rDNA sequences submitted by independent laboratories. Our in-house database contains selected 16S rDNA sequences and is more accurate; however, it does not contain the range of data required to classify more unusual bacteria, so both methods were used to obtain the most accurate results. Despite such measures identification of some species by their $16 \mathrm{~S}$ rDNA sequences is still problematic. There was particular difficulty in identifying members of the Streptococcus mitis group. CLUSTAL analysis of GenBank and inhouse sequences from this group of organisms showed that Streptococcus pneumoniae could reliably be identified but that Streptococcus mitis and Streptococcus oralis cannot be distinguished (K. Harris, unpublished data). However, a few Streptococcus pneumoniae sequences from GenBank were not identified as such by CLUSTAL analysis, indicating that they may have been incorrectly assigned to this species. We have concluded that it is not possible to accurately identify the three species within this group from partial 16S rDNA using BLAST searching of the GenBank database alone. CLUSTAL analysis reliably identifies Streptococcus pneumoniae but the other species from this group are identified as Streptococcus sp. (mitis group).

The potential clinical application of broad-range 16S rDNA PCR is demonstrated in the preliminary review of results from clinical specimens. 16S rDNA PCR provided the sole evidence of the presence of specific bacterial DNA in 70 out of 275 culture-negative specimens; 58 of these were considered to be clinically significant pathogens. A further 13 samples grew CNS but were PCR-positive for clinically significant pathogens. In total therefore, in this selected group of specimens, PCR provided the sole evidence of potentially pathogenic infection in 71 cases. A range of different organisms was detected by PCR that were not detected by culture. Some were unusual and difficult to culture such as Helicobacter sp. (Harris et al., 2002) and Mycoplasma orale, while others were more common organisms that probably failed to grow because of prior empirical treatment with antibiotics. The most common organism detected only by PCR was Streptococcus pneumoniae, an organism that may be difficult to grow because of its tendency to undergo autolysis but also usually covered in empirical antibiotic therapy. Where bacterial infection is diagnosed solely by molecular methods, no information on antibiotic sensitivity is avail- able. In the case of Streptococcus pneumoniae, penicillin resistance is becoming increasingly common. A number of reports have been published that describe the typing of Streptococcus pneumoniae isolates as penicillin-sensitive or resistant by PCR or RFLP analysis (Beall et al., 1998; O’Neill et al., 1999). The genetic determinants of other antibioticresistance mechanisms are also known and many more are being investigated. This information will greatly enhance the clinical utility of molecular techniques for diagnostic microbiology.

While detecting many potentially pathogenic organisms not yielded on culturing, 16S rDNA PCR did not detect all significant infections. There were 44 PCR-negative specimens that were positive by either primary or enrichment culture. Eighteen of these had grown CNS on enrichment culture which were considered to be contaminants. A further two specimens had yielded fungi which could not have been detected by this PCR. However, the remaining 24 specimens represent false-negative PCR results, probably due to failure to detect bacteria present in a sample at a level below the sensitivity of the method. In some cases, culture-positive results were considered to be clinically insignificant, especially if only enrichment culture was positive. The significant species most frequently missed were staphylococci, whose Gram-positive walls are difficult to break down during extraction. However, since 1 October 2000 we have performed mechanical disruption with the Ribolyser during the extraction procedure. This is as effective as lysozyme/ lysostaphin treatment for the lysis of bacterial cell walls but is more rapid (data not shown). Any staphylococci missed by PCR after this modification of the extraction procedure was probably due to low numbers of organisms. The only genus that was detected by culture but never by PCR was Mycobacterium sp. We have shown that mechanical disruption was effective in lysing mycobacterial cells and that the $16 \mathrm{~S}$ rDNA could be amplified (data not shown). Failure to detect Mycobacterium sp. by $16 \mathrm{~S}$ rDNA PCR in clinical specimens was probably due to a small number of organisms present in the specimen. Nucleic acid amplification for the specific detection of mycobacteria has also been hampered by sensitivity issues (Drobniewski et al., 2003). For 10 specimens, PCR and culture result were discordant and PCR failed to detect a clinically significant organism that was detected by culture. This was probably due to a greater amount DNA from a non-viable organism in these specimens than DNA from the viable organism that was detected by culture.

This work has shown that the broad-range $16 \mathrm{~S}$ rDNA PCR can detect and identify DNA from a wide range of organisms from culture or in clinical specimens. Use of broad-range $16 \mathrm{~S}$ rDNA PCR in the routine clinical microbiology service increases the diagnosis of bacterial infection from clinical specimens when used alongside routine culture techniques. PCR does not replace culture. The PCR technique, when performed by a single skilled operator, is rapid (results can be produced within $48 \mathrm{~h}$ ) and reproducible (data not shown). The clinical significance of the result is supported by the analysis of species detected; the majority of DNA detected 
comes from potentially pathogenic micro-organisms in clinically appropriate settings. However, DNA from potentially pathogenic bacteria was not detected at the sensitivity of this assay in the majority of specimens processed, demonstrating that bacterial DNA is not usually found in normally sterile sites. While DNA could be analysed from any specimen, material from usually sterile sites is preferred. Further analysis of the data is under way to determine the clinical impact of the 16S rDNA PCR on patient management in specific patient groups.

\section{ACKNOWLEDGEMENTS}

This work was undertaken by Great Ormond Street Hospital for Children NHS Trust, which received a proportion of its funding from the NHS Executive.

\section{REFERENCES}

Beall, B., Facklam, R. R., Jackson, D. M. \& Starling, H. H. (1998). Rapid screening for penicillin susceptibility of systemic pneumococcal isolates by restriction enzyme profiling of the $p b p 2 B$ gene. J Clin Microbiol 36, 2359-2362.

Bottger, E. C. (1990). Frequent contamination of Taq DNA polymerase with DNA. Clin Chem 36, 1258-1259.

Corless, C. E., Guiver, M., Borrow, R., Edwards-Jones, V., Kaczmarski, E. B. \& Fox, A. J. (2000). Contamination and sensitivity issues with a real-time universal 16S rRNA PCR. J Clin Microbiol 38, 1747-1752.

Doolittle, W. F. (1999). Phylogenetic classification and the universal tree. Science 284, 2124-2128.

Drancourt, M., Bollet, C., Carlioz, R., Martelin, R., Gayral, J. P. \& Raoult, D. (2000). 16S ribosomal DNA sequence analysis of a large collection of environmental and clinical unidentifiable bacterial isolates. J Clin Microbiol 38, 3623-3630.

Drobniewski, F. A., Caws, M., Gibson, A. \& Young, D. (2003). Modern laboratory diagnosis of tuberculosis. Lancet Infect Dis 3, 141-147.

Fredricks, D. N. \& Relman, D. A. (1999). Application of polymerase chain reaction to the diagnosis of infectious diseases. CID 29, 475-488.

Gould, I. M. (1999). A review of the role of antibiotic policies in the control of antibiotic resistance. J Antimicrob Chemother 43, 459-465.

Gould, I. M. (2002). Antibiotic policies and control of resistance. Curr Opin Infect Dis 15, 395-400.

Harris, K. A., Fidler, K. J., Hartley, J. C., Vogt, J., Klein, N. J., Monsell, F. \& Novelli, V. M. (2002). Unique case of Helicobacter sp. osteomyelitis in an immunocompetent child diagnosed by broad-range 16S PCR. J Clin Microbiol 40, 3100-3103.

Janda, J. M. \& Abbott, S. L. (2002). Bacterial identification for publication: when is enough enough? J Clin Microbiol 40, 1887-1891.
La Scola, B., Fenollar, F., Fournier, P.-E., Altwegg, M., Mallet, M.-N. \& Raoult, D. (2001). Description of Tropheryma whipplei gen. nov., sp. nov., the Whipple's disease bacillus. Int J Syst Evol Microbiol 51, $1471-1479$.

Lu, J.-J., Perng, C.-L., Lee, S.-Y. \& Wan, C. C. (2000). Use of PCR with universal primers and restriction endonuclease digestions for detection and identification of common bacterial pathogens in cerebrospinal fluid. J Clin Microbiol 38, 2076-2080.

Lyons, S. R., Griffen, A. L. \& Leys, E. J. (2000). Quantitative real-time PCR for Porphyromonas gingivalis and total bacteria. J Clin Microbiol 38, $2362-2365$

Meier, A., Persing, D. H., Finken, M. \& Bottger, E. C. (1993). Elimination of contaminating DNA within polymerase chain reaction reagents: implications for a general approach to detection of uncultured pathogens. J Clin Microbiol 31, 646-652.

Miles, A. A. \& Misra, S. S. (1938). The estimation of the bacterial power of blood. J Hyg 38, 732-749.

Millar, B. C., Xu, J. \& Moore, J. E. (2002). Risk assessment models and contamination management: implications for broad-range ribosomal DNA PCR as a diagnostic tool in medical bacteriology. J Clin Microbiol 40, 1575-1580

Nadkarni, M. A., Martin, F. E., Jacques, N. A. \& Hunter, N. (2002). Determination of bacterial load by real-time PCR using a broad-range (universal) probe and primers set. Microbiology 148, 257-266.

Nikkari, S., Lopez, F. A., Lepp, P. W., Cieslak, P. R., Ladd-Wilson, S., Passaro, D., Danila, R. \& Relman, D. A. (2002). Broad-range bacterial detection and the analysis of unexplained death and critical illness. Emerg Infect Dis 8, 188-194.

O'Neill, A. M., Gillespie, S. H. \& Whiting, G. C. (1999). Detection of penicillin susceptibility in Streptococcus pneumoniae by $p b p 2 b$ PCRrestriction fragment length polymorphism analysis. J Clin Microbiol 37, $157-160$.

Rantakokko-Jalava, K., Nikkari, S., Jalava, J. \& 8 other authors (2000). Direct amplification of rRNA genes in diagnosis of bacterial infections. J Clin Microbiol 38, 32-39.

Relman, D. A., Schmidt, T. M., MacDermott, R. P. \& Falkow, S. (1992). Identification of the uncultured bacillus of Whipple's disease. $N$ Engl J Med 327, 293-301.

Trotha, R., Hanck, T., Konig, W. \& Konig, B. (2001). Rapid ribosequencing -an effective diagnostic tool for detecting microbial infection. Infection 29, 12-16.

Wilson, K. H., Blitchington, R., Frothingam, R. \& Wilson, J. A. (1991). Phylogeny of the Whipple's-disease-associated bacterium. Lancet 51, 221-271.

Yamamoto, Y. (2002). PCR in diagnosis of infection: detection of bacteria in cerebrospinal fluids. Clin Diagn Lab Immunol 9, 508-514. 